\title{
Safe use of capecitabine-cisplatin in metastatic gastric carcinoma with severe liver dysfunction: a case report from Algeria
}

\author{
Lasgaa Meryem ${ }^{1,2}$, Ghomari Soumia ${ }^{2,3}$, Boudali Bouchra $^{1}$
}

${ }^{1}$ MD. Medical Oncology Specialist, Medical Oncology Departement of Public Hospital of Ghazaouet, Tlemcen, Algeria

${ }^{2}$ Laboratory Toxicomed, University Abou Beker Belkaid, Tlemcen, Algeria

${ }^{3}$ MD, Professor, Medical Oncology Department of University Hospital of Tlemcen, Tlemcen, Algeria

\section{Type of article: Case report}

\begin{abstract}
Due to its high incidence and poor prognosis, gastric cancer is an important health problem worldwide. The liver is the most frequent site of metastases. Advanced cancer in the setting of liver dysfunction poses a dilemma for physicians, as many cancer chemotherapeutic agents undergo hepatic metabolism. This paper reports the case of a patient with liver failure due to liver metastases of gastric cancer. The initial liver function tests showed an elevation of transaminases (aspartate amino transferase $180 \mathrm{IU} / \mathrm{l}$, alanine aminotransferase $110 \mathrm{UI} / \mathrm{l}$ ), hyperbilirubinemia (total bilirubin at $24 \mathrm{mg} / \mathrm{dl}$ ), alkaline phosphatase at $1127 \mathrm{UI} / 1$ and elevation of tumor markers (carcinoembryonic antigen $>1000 \mathrm{ng} / \mathrm{ml}$ and CA19,9 at $180 \mathrm{UI} / \mathrm{l}$ ). We initiated capecitabine/cisplatin based combination chemotherapy. Our data supports the safety and feasibility of cisplatin-capecitabine regimen in patients with severe liver dysfunction secondary to liver metastases of gastric cancer.
\end{abstract}

Keywords: Gastric cancer, Liver dysfunction, Capecitabine, Cisplatin

\section{Introduction}

In Algeria, incidence of stomach cancer was estimated at 3.7/100000 in women and 7.6/100000 in men, according to GLOBOCAN 2012, making it the fifth most common malignancy, after cancer of the lung, breast, colorectal and prostate (1). The liver is the most frequent site of metastases in gastric cancer. Metastatic liver involvement may result in liver dysfunction, indicated by increased bilirubin (hyperbilirubinemia), increased level of cholestatic parameters (gamma-glutamyl transferase and alkaline phosphatase) and transaminases as well as impaired liver synthesis (e.g. low albumin). Liver has a very important role in the metabolism of drugs; thus, the administration of chemotherapy to gastric cancer patients with liver dysfunction requires careful consideration (2). We report here, on a patient with extensive liver metastasis and secondary liver dysfunction who was treated with capecitabine and cisplatin with manageable toxicity.

\section{Case presentation}

A 64-year-old patient presented with four months' history of epigastralgia after weight loss which had been ongoing for a year. His performance status was estimated to be ECOG 2. The physical examination showed a hepatomegaly and scleral icterus. Computerized tomography (CT) scan and ultrasonography of the abdomen and pelvis revealed thickening of the lesser gastric curvature and multiple solid masses in the liver (Figure1). Endoscopy and biopsy confirm a cancer of the antrum of stomach. The liver function tests showed increased transaminases (aspartate amino transferase $180 \mathrm{IU} / \mathrm{l}$, alanine aminotransferase $110 \mathrm{UI} / \mathrm{l}$ ) hyperbilirubinemia (total bilirubin at $24 \mathrm{mg} / \mathrm{dl}$ ), alkaline phosphatase at $1127 \mathrm{UI} / \mathrm{l}$, and elevation of tumor markers (carcinoembryonic antigen $>1000 \mathrm{ng} / \mathrm{ml}$ and CA19,9 at $180 \mathrm{UI} / \mathrm{l})$. The patient was treated with cisplatin $\left(75 \mathrm{mg} / \mathrm{m}^{2}\right)$ on day 1 , and capecitabine $(1,000 \mathrm{mg} / \mathrm{m} 2$

\section{Corresponding author:}

Dr. Lasgaa Meryem, cite el nour n²6 Mansourah, Tlemcen, Algeria.

Tel.: +213556448603, Email: dr_lasgaa@hotmail.fr

Received: December 16, 2016, Accepted: May 18, 2017, Published: August 2017

iThenticate screening: February 09, 2017, English editing: July 20, 2017, Quality control: August 06, 2017

This article has been reviewed / commented by four experts

(C) 2017 The Authors. This is an open access article under the terms of the Creative Commons Attribution-NonCommercialNoDerivs License, which permits use and distribution in any medium, provided the original work is properly cited, the use is non-commercial and no modifications or adaptations are made. 
orally twice daily) on days $1 \sim 14$ of a 21 -day cycle. Nausea, emesis and diarrhea grade 2 were noted during the first cycle but these toxicities were manageable. Total bilirubin, which was high $(24 \mathrm{mg} / \mathrm{dl})$ on admission, decreased to $10 \mathrm{mg} / \mathrm{dL}$ and aspartate amino transferase $32 \mathrm{IU} / \mathrm{l}$ after the first cycle. After three cycles of chemotherapy, his total bilirubin decreased to within the normal range $(1.05 \mathrm{mg} / \mathrm{dL})$. CT scan revealed that the tumor nodes were markedly reduced (Figure2); his carcinoembryonic antigen levels decreased to $300 \mathrm{ng} / \mathrm{ml}$ from $1000 \mathrm{ng} / \mathrm{ml}$ and CA19-9 to $1.09 \mathrm{ng} / \mathrm{ml}$ from $378 \mathrm{ng} / \mathrm{ml}$. He has received 9 cycles of capecitabine-cisplatin with ongoing clinical benefit and good tolerance of treatment.

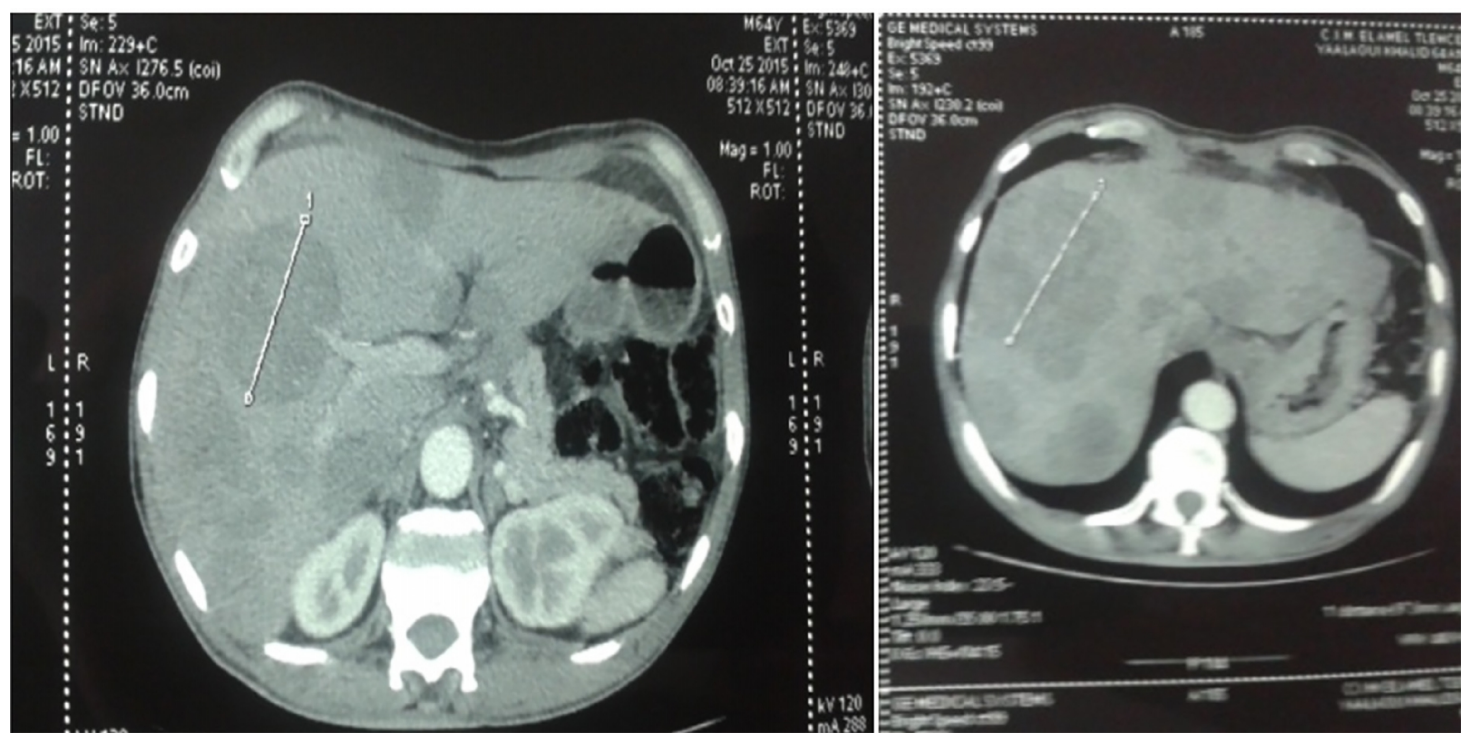

Figure 1. CT scan of the abdomen (A and B) shows multiple variable-sized metastatic nodular lesions in the liver.

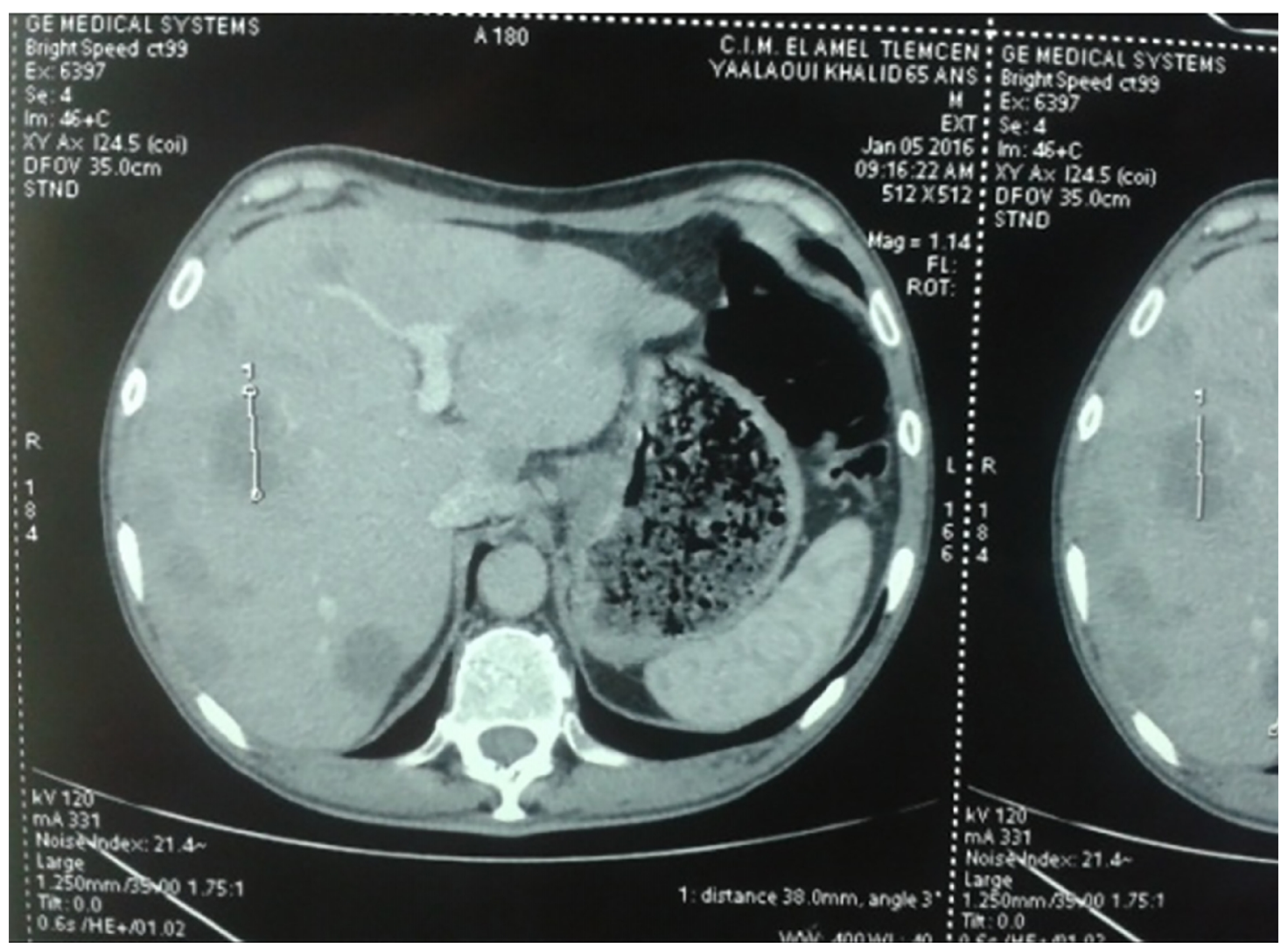

Figure 2. CT scan shows that the metastatic liver nodules were markedly reduced after three cycles of chemotherapy 


\section{Discussion}

Chemotherapy has been shown to improve survival and quality of life in patients with metastatic gastric carcinoma. Several chemotherapeutic agents have activity in gastric cancer $(3,4)$. These include 5 -FU, capecitabine, cisplatin, oxaliplatin, irinotecan, and taxane. 5-FU is a uracil analogue and antimetabolite that is metabolized mainly in the liver by dihydropyrimidine dehydrogenase (DPD). Although 5-FU is fairly safe to use in patients with liver dysfunction, regular monitoring of liver tests is advised (5). Capecitabine, a prodrug of 5-Fluororuracil (5-FU) is activated through three enzymatic reactions. Twelves et al. (6) have compared the use of capecitabine in patients with moderate hepatic dysfunction secondary to liver metastases to patients with normal liver function. Results have demonstrated that there are no significant differences in the pharmacokinetic parameters in the two groups, thus no need for adjustment of dose in this category of patients. Many studies have demonstrated that cisplatin is a pilot molecule in the treatment of metastatic gastric cancer; its exclusive renal excretion allow its administration without adjustment dose in patients with liver dysfunction. In a study of 11 patients with liver failure caused by metastatic breast cancer treated with cisplatin at doses of $75 \mathrm{mg} / \mathrm{m}^{2}$ every 21 days, and vinorelbine at $20 \mathrm{mg} / \mathrm{m} 2$ on days 1 and 8 of a 21-day of cycle, results demonstrated an improvement in liver failure in 10 patients and partial response in 7 cases (7). One death, from intracerebral hemorrhage, was recorded. The BC cancer agency has declared that no adjustment dose is required in patients with liver dysfunction. Oxaliplatin is a third-generation platinum which can replace, with the same efficiency, the cisplatin in the treatment of metastatic gastric cancer. A "phase 1 study" conducted by The Organ Dysfunction Working Group of the National Cancer Institute demonstrated that oxaliplatin administrated at the standard dose of $130 \mathrm{mg} / \mathrm{m}^{2}$ was well tolerated for patients with all liver failure without alteration in the clearance of the platinum species from the plasma, but they did not report the rate of bilirubin in the severe liver dysfunction group $(8,9)$. According to BC cancer agency, no adjustment dose is required for mild to moderate failure $(10,11)$.

\section{Conclusions}

This report suggests that capecitabine-cisplatin may be a safe and efficacious treatment for patients with hepatic dysfunction, but more clinical data is needed to confirm these results. Liver dysfunction resulting from liver metastases in patients with gastric carcinoma should not lead to therapeutic delay, but the indication of chemotherapy for this category of patient must be cautious because no recommendations are available and clinical data in this clinical situation are limited.

\section{Acknowledgments:}

The authors express their gratitude to the University of Abou Bekr Belkaïd in Tlemcen, Algeria, and Toxicomed laboratory represented by its head professor, for her advice and encouragement. Additionally, they are grateful to the director of the Public Hospital of Ghazaouet, Tlemcen, Algeria for the means which he has implemented for the good coverage of the cancer patients. The authors also thank the department of epidemiology represented by Profeswsor Meguenni and Abdeldjalil Khelassi for organizing the International Conference on Health Sciences and Medical Technologies (CHSMT'16).

\section{Conflict of Interest:}

There is no conflict of interest to be declared. We declare that this article is published for free funded by the journal because it wins the price of best presentation at ICHSMT'16.

\section{Authors' contributions:}

All authors contributed to this project and article equally. All authors read and approved the final manuscript.

\section{References:}

1) WHO; International Agency for Research on Cancer. globocan 2012: Estimated Cancer Incidence, Mortality and Prevalence Worldwide in 2012. Available from: http://globocan.iarc.fr/Default.aspx.

2) Sasson AR, Sigurdson ER. Surgical treatment of liver metastases. Semin Oncol. 2002; 29(2): 107-18. doi: 10.1053/sonc.2002.31676. PMID: 11951208.

3) Pyrhonen S, Kuitunen T, Nyandoto P, Kouri M. Randomized comparison of fluorouracil, epidoxorubicin and methotrexate (FEMTX) plus supportive care with supportive care alone in patients with non-resectable gastric cancer. Br J Cancer. 1995; 71(3): 587-91. doi: 10.1038/bjc.1995.114. PMID: 7533517, PMCID: PMC2033628. 
4) Glimelius B, Ekstrom K, Hoffman K, Graf W, Sjoden PO, Haglund U, et al. Randomized comparison between chemotherapy plus best supportive care with best supportive care in advancer gastric cancer. Ann Oncol. 1997; 8(2): 163-8. doi: 10.1023/A:1008243606668. PMID: 9093725.

5) Fleming GF, Schilsky RL, Schumm LP, Meyerson A, Hong AM, Vogelzang NJ, et al. Phase I and pharmacokinetic study of 24-hour infusion 5FU and leucovorin in patients with organ dysfunction. Ann oncol. 2003; 14(7): 1142-7. PMID: 12853359.

6) Twelves C, Glynne-jonesR ,Cassidyj, SchullerJ ,Goggin T , Roos B , Banken L, Utoh M, Wridekamm E, Reigner B :Effect of hepatic dysfunction due to liver metastases on the pharmacokinetics of capecitabine and its metabolites. Clin cancer Res $1999 \mathrm{Jul} ; 5(7): 1696-702$.

7) Sharma RA, Decatris MP, Santhanam S, Roy R, Osman AE, Clarke CB, et al. Reversibility of liver failure secondary to metastatic breast cancer by vinorelbine and cisplatin chemotherapy. Cancer Chemother Pharmacol. 2003; 52(5): 367-70. doi: 10.1007/s00280-003-0679-8. PMID: 12879281.

8) Doroshow JH, Synold TW, Gandara D, Mani S, Remick SC, Mulkerin D, et al. Pharmacology of oxaliplatin in solid tumor patients with hepatic dysfunction: a preliminary report of the National Cancer Institute Organ Dysfunction Working Group. Semin Oncol. 2003; 30(4 Suppl 15): 14-9. PMID: 14523790.

9) Hwang SJ, Park JW, Lee SD, Kim GJ, Sin CH, Nam SH, et al. Capecitabine and Oxaliplatin (XELOX) for the Treatment of Patients with Metastatic Gastric Cancer and Severe Liver Dysfunction. Korean J Intern Med. 2006; 21(4): 252-5. doi: 10.3904/kjim.2006.21.4.252. PMID: 17249509, PMCID: PMC3891032.

10) UCLH. Dosage Adjustment for Cytotoxics in Hepatic Impairment. 2009.

11) Quidde J, Azémar M, Bokemeyer C, Arnold D, Stein A. Treatment approach in patients with hyperbilirubinemia secondary to liver metastases in gastrointestinal malignancies: a case series and review of literature. Ther Adv Med Oncol. 2016; 8(3): 144-52. doi: 10.1177/1758834016637585. PMID: 27239232, PMCID: PMC4872252. 